\title{
BREVE ANÁLISE DA PLATAFORMA DE AVALIAÇÃO DE APRENDIZAGEM EM TEMPO REAL INSERIDA NO PROGRAMA DE MESTRADO EM LINGUÍSTICA APLICADA
}

\author{
Brief analysis of the Real-time Learning Assessment Platform inserted in the Applied \\ Linguistics Master's Program
}

Luiza Ribeiro de MELO - UNITAU
Rubens Eduardo GOMES - UNITAU

RESUMO: Este artigo apresenta um breve exame da Plataforma de Avaliação de Aprendizagem em tempo real inserida no contexto do Programa de Mestrado em Linguística Aplicada. A justificativa da análise guarda relação quanto ao papel da plataforma educacional enquanto ferramenta útil na construção de saberes na contemporaneidade. $\mathrm{O}$ objetivo geral do artigo foi investigar quais são as principais tendências filosóficas e pedagógicas que permeiam este site. $\mathrm{O}$ objetivo específico da investigação foi apurar a viabilidade da plataforma educacional no contexto em que é utilizada. A metodologia utilizada neste trabalho consistiu em uma breve descrição do site seguida por uma sondagem em diferentes conteúdos compartilhados na plataforma. Os dados revelaram que este site pode ser considerado como uma ferramenta de Web 2.0, contribui para direcionar os estudos dos aprendentes, possui uma abordagem com tendências filosóficas transformadoras e reprodutoras de informações e conhecimentos por meio de uma pedagogia voltada para multiletramentos direcionada adequadamente ao público adulto. Pode-se concluir que o uso de plataformas educacionais adequadas ao contexto e aos objetivos educacionais pode contribuir com a formação dos aprendentes.

\section{PALAVRAS-CHAVE: Aprendente; Multiletramentos; Avaliação da aprendizagem; Web} 2.0.

ABSTRACT: This article presents a brief examination of the real-time Learning Assessment Platform in the context of an applied linguistics Master's program. This analysis is justified by the role of the educational platform as a useful tool for constructing various types of knowledge in the contemporary era. The general objective of this article was to investigate the main philosophical and educational trends that guide this website. The specific objective of this inquiry was to assess the viability of the educational platform in the context where it is used. The methodology used in this study comprises a short description of the website, followed by a survey of different contents shared on the platform. Data showed that this website can be considered a web 2.0 tool which can help guide learners in their studies. Its approach has transformative philosophical trends that reproduce information and knowledge through pedagogy targeted at the creation of multiliteracies, suitably directed at the adult public. In conclusion, the use of educational platforms that are adequate to their context and suited to educational goals can enhance the education of learners.

KEYWORDS: Learner; Multiliteracies; Learning Assessment; Web 2.0.

\footnotetext{
1 Professora na rede municipal de São Sebastião, SP, mestranda em 2016 no Programa de Mestrado em Linguística Aplicada na Universidade de Taubaté. E - mail: lurime65@hotmail.com

2 Professor efetivo de Português e Inglês na rede pública do estado de São Paulo, com sede em Diadema, mestrando em 2016 no Programa de Mestrado em Linguística Aplicada na Universidade de Taubaté. E - mail: professorrubens@ib est.com.br.
} 


\section{INTRODUÇÃO}

O presente trabalho examina, brevemente, a Plataforma de Avaliação de Aprendizagem em tempo real ${ }^{3}$ disponível na internet, inserida na disciplina de Teorias Linguísticas, no Programa de Mestrado em Linguística Aplicada (L.A.) da Universidade de Taubaté - SP (UNITAU). Para tanto, são apontadas as informações gerais sobre este site, assim como a estrutura pedagógica que serve de base para o modelo de ensino a que se propõe.

O objetivo geral do artigo foi investigar quais são as principais tendências filosóficas da educação que permeiam o site, bem como as tendências pedagógicas postas em prática com vistas às tarefas, exercícios, provas, proposições de leituras e referências que fundamentam tais atividades no contexto do Programa de Mestrado em L.A - UNITAU. O objetivo específico da investigação foi apurar a viabilidade da plataforma educacional no contexto em que é utilizada. Para tanto, levamos em consideração as características mais marcantes que permeiam os processos de ensino-aprendizagem, a relação professor e aluno, aluno e aluno.

A justificativa da análise guarda relação quanto ao papel da plataforma educacional enquanto ferramenta útil na construção de saberes na contemporaneidade.

Empreendemos nosso trabalho baseando-nos, principalmente, nos pressupostos a respeito dos usos das Tecnologias de Informação e Comunicação (TIC), nas contribuições de Luckesi (1994), Coll e Monereo (2010), Gil (2012), entre outros. A metodologia empregada para realização desta pesquisa compreendeu, primeiramente, fazer uma breve descrição do site com o propósito de identificar o que ele oferece na prática ao usuário. Em seguida, procedemos a uma análise de conteúdos compartilhados na plataforma para verificar quais são as tendências filosóficas e pedagógicas que permeiam tais conteúdos, bem como procedemos com um exame a respeito das interações que acontecem por meio do site.

\section{A PLATAFORMA, O MATERIAL DIDÁTICO VIRTUAL E A INTERAÇÃO}

O site orienta aos usuários que utilizem o navegador de internet denominado Mozilla Firefox para total e ampla utilização de todos os recursos disponíveis na plataforma: textos; vídeos; apresentações de slides. O site oferece cursos ligados à graduação, à extensão universitária e à pós-graduação, logo, não atende apenas ao Mestrado em L.A. da UNITAU. Porém, no caso de nossa análise, acessamos o Material Didático Virtual (MDV) referente à disciplina de Teorias Linguísticas, que é ministrada em aulas presenciais no Programa de Mestrado em L.A. na UNITAU utilizando o MDV.

\footnotetext{
${ }^{3}$ Disponível em: <http://www.professorcarlosoliveira.com/MDV/Plataforma.html> Acesso em: 29 ago. 2016.
} 
O trabalho com o MDV compreende princípios baseados em texto, em recursos com hipertexto, em multimodalidade de gêneros e manipulação de recursos que envolvem TIC. O site é uma plataforma educacional que visa à avaliação da aprendizagem do aluno ali matriculado. Reiteramos que nossa análise está restrita ao contexto do Programa de Mestrado L.A. da UNITAU. Devido a tal vínculo, o responsável pelo site tem os contatos de e-mail dos alunos matriculados. Por isso, o primeiro acesso do aprendente à plataforma educacional acontece após um contato do responsável pelo site com o aprendente via e-mail conferindo-lhe uma senha de acesso ao ambiente virtual de aprendizagem. A figura 1 representa a página principal do aluno.

Figura 1: Revista Virtual

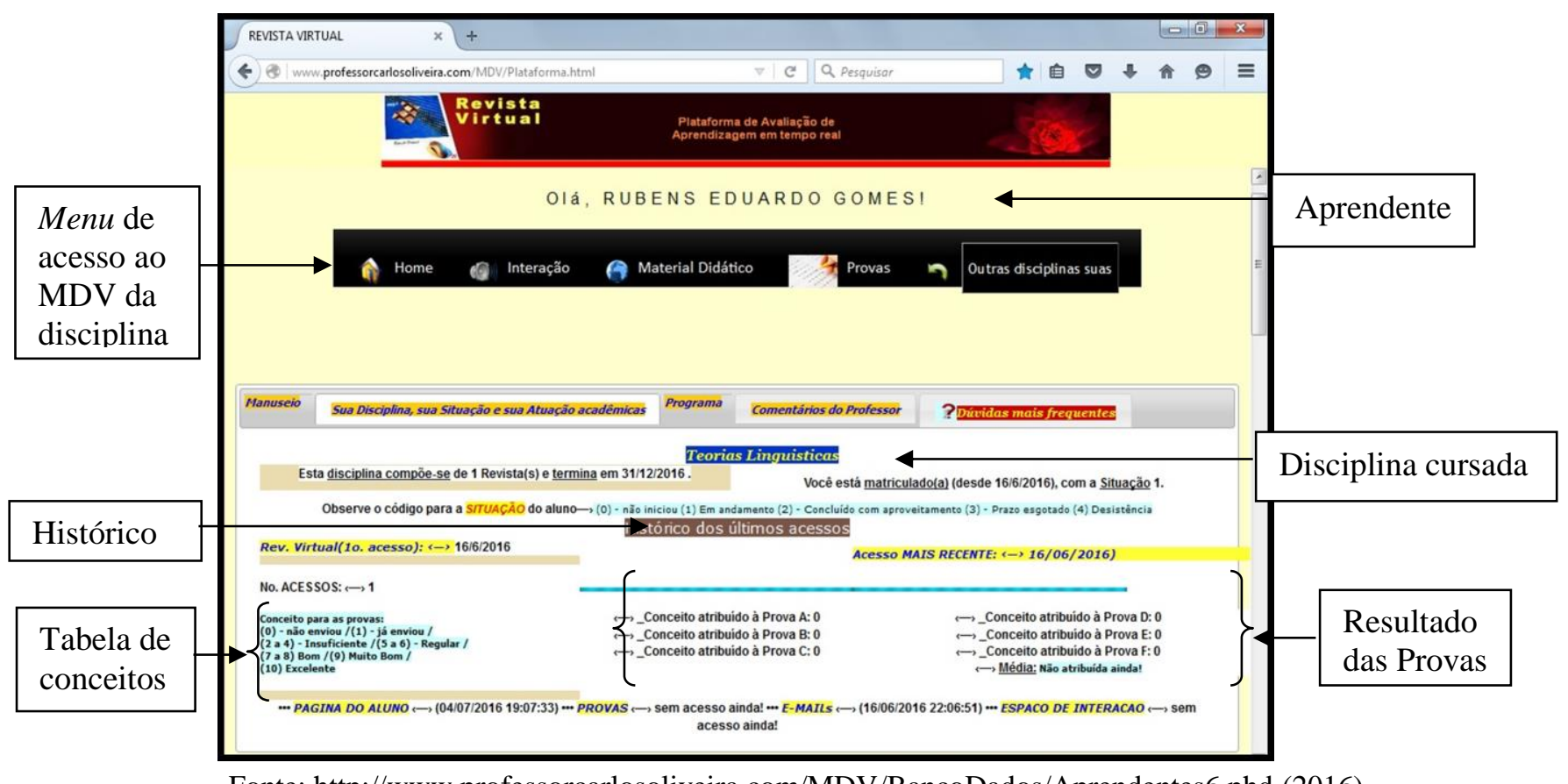

Fonte: http://www.professorcarlosoliveira.com/MDV/BancoDados/Aprendentes6.phd (2016)

Conforme podemos observar na figura 1, esta área é definida pela disciplina que o aprendente cursa bem como o andamento e rendimento nos estudos. Trata-se de informações importantes disponibilizadas logo no início do site. Uma delas é sobre as avaliações, denominadas como Provas que, apesar de estarem organizadas na sequência alfabética, não significa que o aprendente deva seguir esta sequência para realizá-las. Outra informação em destaque é o Histórico dos últimos acessos do aprendente ao MDV bem como a sua situação no curso no momento do acesso. Já as informações que constam abaixo do histórico ajudam ao aprendente a acompanhar o próprio rendimento durante o curso, por meio dos conceitos atribuídos às provas.

Nesse primeiro acesso, o internauta é direcionado para assistir a um vídeo que ensina sobre a funcionalidade da plataforma. Tal ação demonstra aspectos do aporte filosófico e pedagógico 
utilizado nos trabalhos realizados pelo site, uma vez que é preciso assistir ao vídeo que dá orientações a respeito da plataforma educacional.

A necessidade de assistir ao vídeo faz referência à interação entre professor e aluno, que nesta situação de aprendizagem se dá por meio do contato indireto entre ensinante e aprendente intermediado pelo vídeo. Aprendente é o termo utilizado no site em relação à pessoa matriculada com acesso à plataforma. Esse termo indica, segundo Cruz (2011), uma tendência pedagógica e psicopedagógica.

O educando depende do educador para aprender, mas, no entanto, o trabalho intelectual é de quem aprende. Se quem aprende não se dispuser ao trabalho intelectual não haverá aprendizagem, haverá frustração. Assim, quem ensina também se sentirá frustrado. Esta relação revela uma interação de contra dependência, pois ao mesmo tempo em que há o poder do ensinante sobre o aprendente, há, também, um enorme poder de quem aprende sobre quem ensina, porque o sucesso de quem ensina depende, fundamentalmente, de que o aprendente realize o essencial no trabalho. (CRUZ, 2011, p. 27).

$\mathrm{Na}$ perspectiva desta pedagogia, o ensinante também aprende na interação com o aprendente. A esse respeito, Vasconcellos (1992, p. 5-6) afirma:

O primeiro passo, portanto, do educador, enquanto articulador do processo de ensinoaprendizagem, deverá ser no sentido de conhecer sua realidade, ou seja, conhecer a realidade com a qual vai trabalhar. Para isto, inicialmente o professor tem que aprender com seus alunos.

Vasconcellos (1992) argumenta que não é o caso de tomar conhecimento a respeito dos aspectos íntimos dos alunos, mas, de acordo com o autor (1992, p. 6), é necessário conhecer aspectos relacionados às “[...] necessidades, interesses, representações, valores, experiências, expectativas, problemas que se colocam [...]" como uma possibilidade para articular o conhecimento a ser (re)construído. Com esse propósito, Vasconcellos (1992, p. 6) afirma que “o educador deverá entender o educando, seu ponto de vista, para saber como ajudá-lo na construção do conhecimento (seja pelo estabelecimento de contradição, pela problematização, etc.)". Logo, a interação elaborada mediante as atividades propostas na plataforma pressupõe que o ensinante aprenda com o aprendente.

A fim de aprofundar o entendimento a respeito do uso consciente do termo ensinante e aprendente, recorremos à explicação de Andrade (2006):

Às palavras ensinante, aprendente, atribuímos o valor de conceitos. Não são equivalentes a aluno e professor, pois estes fazem referência a lugares objetivos em um dispositivo pedagógico, enquanto aqueles indicam um modo subjetivo de situar-se. Ensinante/aprendente pauta-se numa relação transferencial, que se define a partir de lugares subjetivos e de um projeto identificatório. 
Assim, o uso do termo aprendente se apresenta adequado para este ambiente virtual de aprendizagem, uma vez apoiado em uma pedagogia que objetiva a formação de um sujeito comprometido com o seu próprio desenvolvimento prático mediado pelo aporte teórico sugerido no site e pelas diversas possibilidades de interação. O conhecimento construído a partir dessa forma pode tornar-se significativo, segundo Cruz (2011, p. 27), "porque este saber não nasce do mero ensino, ou da mera aprendizagem, mas se constrói no aprender a aprender e no aprender a pensar".

Considera-se, neste contexto, que o aprendente está disposto a aprender. Logo, o aprendente deve estar disposto a uma interação com outros em igual situação e/ou com o ensinante. No âmbito desta breve análise, temos como aprendentes os alunos matriculados no curso de Mestrado em L.A. da UNITAU. Embora haja aulas presenciais para tais alunos, parte importante da avaliação da aprendizagem ocorre na plataforma educacional com o cumprimento de tarefas. Por meio da plataforma, o papel de ensinante envolve uma interação que foca a construção dos conteúdos ministrados. Nesse sentido, Cruz (2011, p. 28) afirma:

Fica explícito, então, que no centro desta relação fica a prática de quem aprende, não a prática de quem ensina. Isto chama atenção para o papel do educador - mediar criativamente, desafiadoramente e intencionalmente as ações educativas para que o educando possa aprender.

Observamos que a tendência filosófica e pedagógica que permeia esta plataforma educacional visa o aprendizado do aluno. Para termos de comparações, a pedagogia tradicional conteudista que foca o erro e o acerto não tem espaço neste contexto que objetiva a construção consciente do conhecimento.

Ao iniciar os estudos online, caso o aluno tenha correspondências de seu interesse, uma caixa de diálogo é aberta sobrepondo-se à página do aluno avisando-lhe da existência de $e$-mail. Pedagogicamente, isto direciona o aluno para prováveis contatos com parceiros de curso, avisos importantes, ou mesmo algum tipo de pendência. Porém, conforme a figura 1 demonstra, o aprendente pode ter acesso a outras informações.

Figura 2: Barra de menu

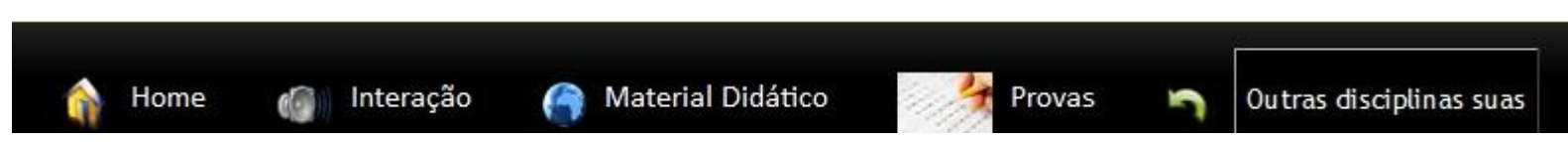

Fonte: http://www.professorcarlosoliveira.com/MDV/BancoDados/Aprendentes6.phd (2016)

Esta barra de menu, que destacamos na figura 2, está situada na página do aluno e o direciona para a navegação na plataforma, conforme seu interesse naquele momento. Por meio 
dela, o usuário acessa uma lista de comandos a serem executados, e/ou uma lista de comandos que permitem executar alguma das opções propostas. Esta barra de menu usa a primeira e última opção com o acesso na forma de botão, ou seja, o usuário precisa clicar no botão Home para ir para a página principal, ou clicar no botão Outras disciplinas suas para acessar outras disciplinas que está matriculado. Se o aprendente escolher a palavra Interação, ele tem a possibilidade de ser direcionado para o próprio espaço de interação, para os e-mails, para a interação com os colegas ou com o professor. O item Material Didático disponibiliza duas opções ao usuário do sistema. A primeira opção é a versão disponível na internet da Revista Virtual que contém os assuntos relativos ao curso do aprendente. A segunda trata-se do mesmo MDV com a possibilidade de ser impresso. O item Provas da barra de menu disponibiliza quatro opções, sendo: a) critérios de avaliação; b) devolutivas de provas; c) (Re)fazer suas provas; d) enviar suas provas.

Ao acessar a Revista Virtual no item Material Didático, uma nova guia é aberta para que o aprendente tenha acesso ao MDV. No caso de nossa análise, acessamos a disciplina de Teorias Linguísticas. A figura 3 representa este MDV.

Figura 3: Teorias Linguísticas

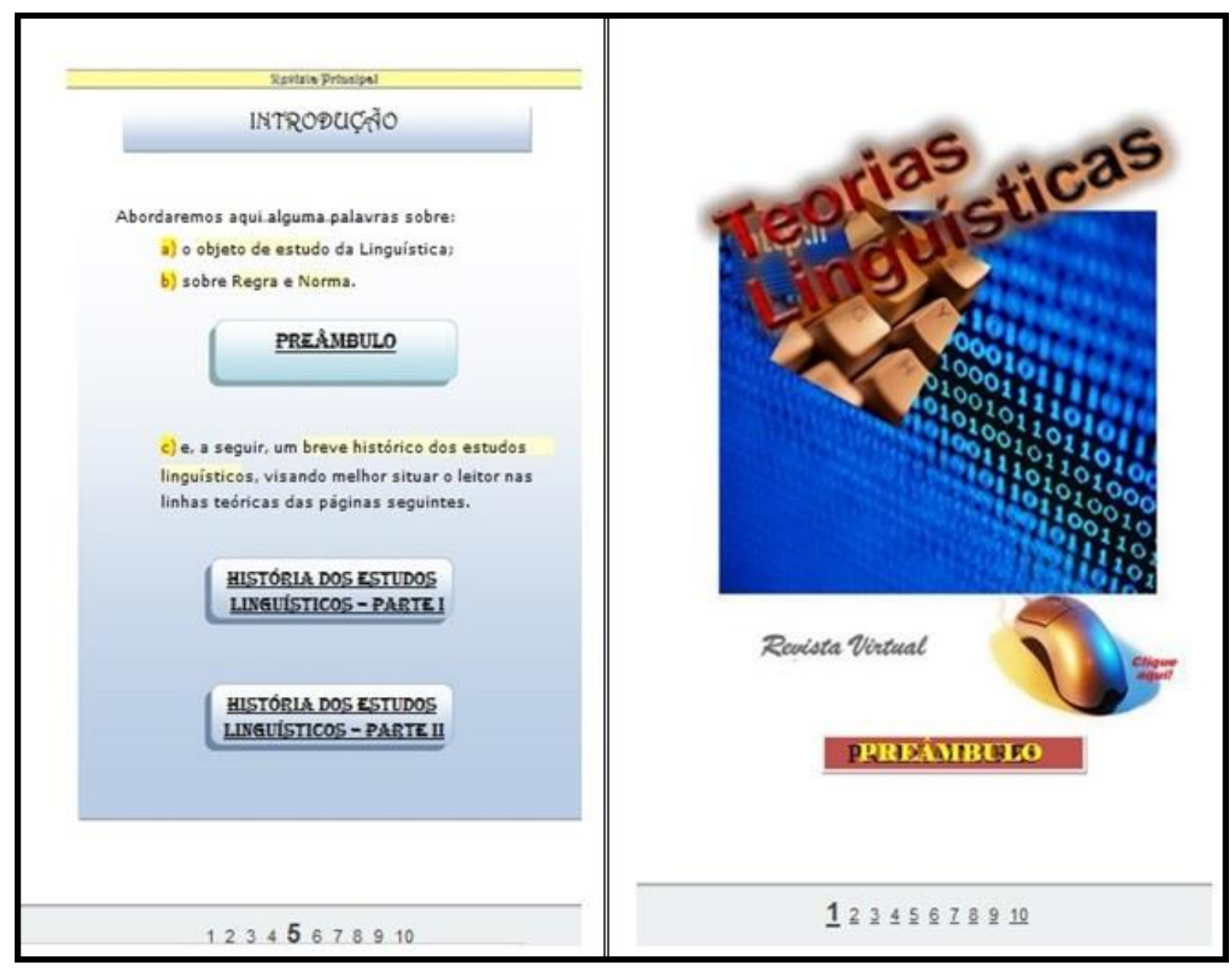

Fonte: http://www.professorcarlosoliveira.com/MDV/Plataforma.html (2016) 
No caso da imagem anterior, ela representa parte do MDV. Na página deste material clicamos no botão denominado Preâmbulo. Esse hiperlink abre uma nova guia com o Preâmbulo completo. Cada botão conduz à informação que ele representa e condiz com uma parte do MDV a ser estudada. As recomendações de referências para ampliação dos temas abordados é parte integrante do MDV. Nesse aspecto, compete ao aprendente o esforço por estudar a disciplina. Esse ato de esforçar-se para estudar, para Freire (1999), não precisa essencialmente ocorrer dentro das paredes de uma instituição como uma escola, ou neste caso, a universidade. Ao contrário, para o autor (1999), o ato do esforço para o estudo pode ocorrer no momento e local que forem mais próprios e adequados a cada indivíduo. Ainda segundo o autor, é necessário que a pessoa tenha disposição para isso e que, dentro de suas possibilidades, estude.

Selecionamos uma das provas - figura 5 - para nossa próxima observação a respeito da plataforma. O acesso é por meio da barra de menu, figura 4, no item Provas, no terceiro comando identificado como (Re)fazer suas provas. A figura 5 representa a nova guia aberta.

Figura 4: Barra de menu, item: Provas 
Figura 5: Refazer Provas

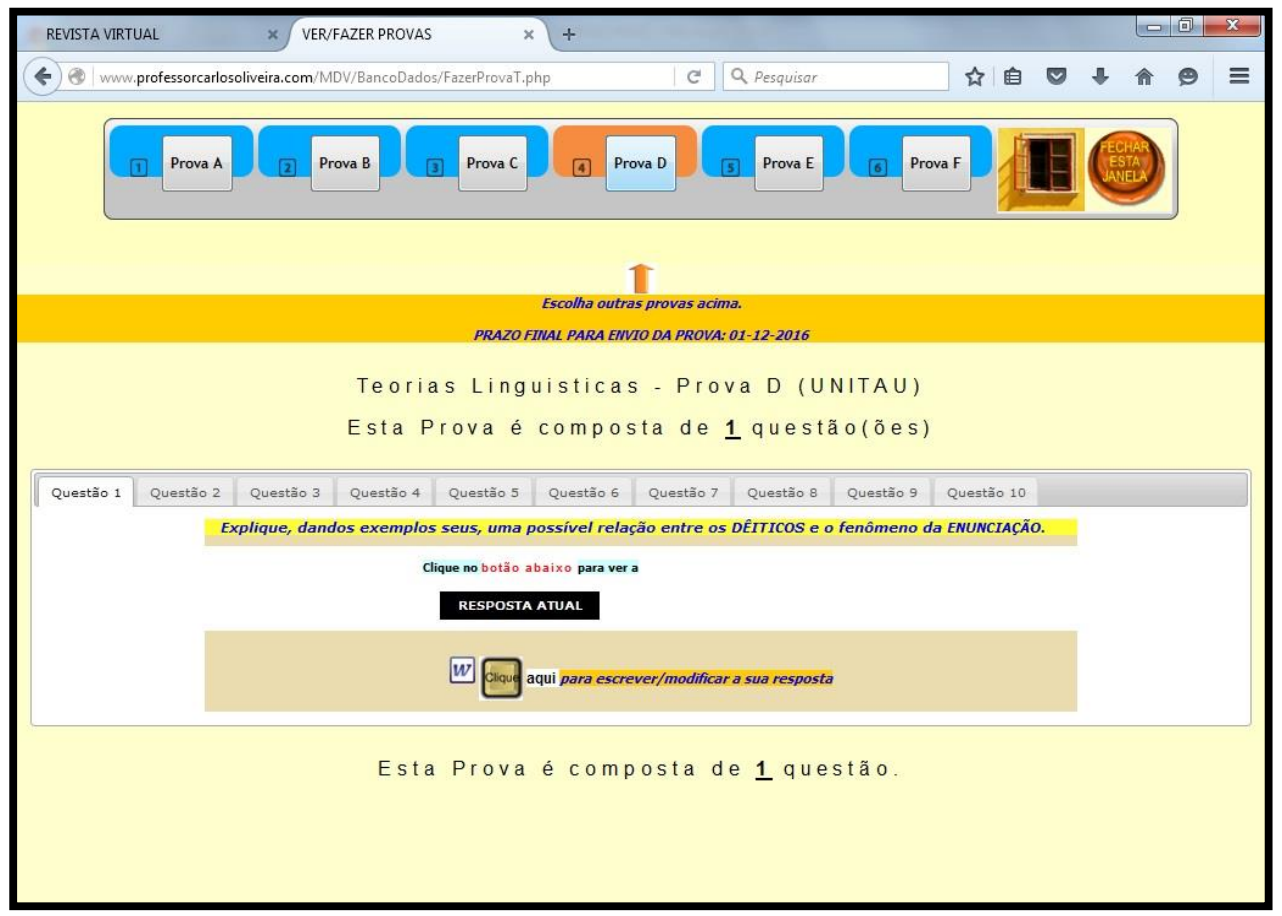

Fonte: http://www.professorcarlosoliveira.com/MDV/BancoDados/FazerProvaT.php (2016)

Na figura 5, podemos observar que são apresentadas seis provas identificadas e listadas em ordem alfabética de A até F. A guia aberta denomina-se Ver/fazer provas. A Prova D, em destaque na figura 5, é a única que possui apenas 1 questão a ser elaborada pelo aprendente. Todas as demais possuem 2 questões. Porém, a Prova $F$ não é realizada no site, e sim presencialmente no curso de Mestrado em L.A. Entretanto, o resultado para o aluno é disponibilizado na plataforma tanto quanto possível de acordo com o término dos trabalhos presenciais, dentro dos prazos estipulados pelo professor.

É importante observar que o aprendente precisa selecionar a tarefa elaborada e enviá-la, utilizando o item Enviar suas provas que está disposto na lista de comandos da barra de menu Provas. Caso não haja confirmação deste envio, a tarefa não é tida por enviada para avaliação do professor. E conforme o aprendente confirma o envio ao professor das provas feitas, ao acessá-la novamente, um quadro de diálogo o avisa que a ação já ocorreu, conforme ilustra a figura 6. 
Figura 6: Caixa de diálogo

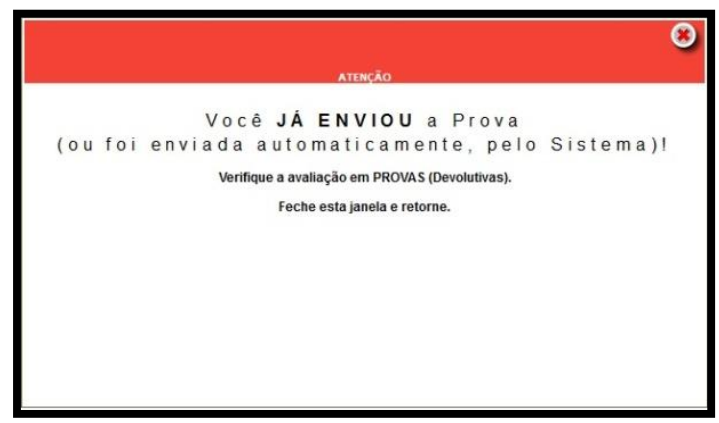

Fonte: http://www.professorcarlosoliveira.com/MDV/Plataforma.html (2015)

A página com menu principal, figura 1, também é importante porque nela há fácil acesso aos comentários postados pelo professor em relação às tarefas executadas, uma vez que o trabalho proposto na plataforma é assincrônico, ou seja, o aprendente não depende que o professor esteja online no momento da postagem de atividades.

Um fato importante a ser observado é que todas as provas com inadequações podem ser refeitas, obedecendo aos prazos estipulados, com exceção da Prova $F$, uma vez que esta acontece em aula. O propósito em permitir que o aprendente refaça tarefas é possibilitar que ele alcance os objetivos propostos para cada prova, sempre tendo em vista os critérios de avaliação que são postos claramente para o aprendente. Tal fato harmoniza-se aos princípios norteadores do uso do MDV na Plataforma de Avaliação de Aprendizagem em tempo real.

\section{FUNDAMENTAÇÃO TEÓRICA}

A Educação a Distância (EAD) tem desempenhado importante papel na difusão de informações e conhecimentos para vários segmentos da sociedade. Tal uso vincula-se grandemente às possibilidades de acesso ao conhecimento por meio das TIC. Embora haja real necessidade de uso de material tecnológico envolvendo-as, a EAD é utilizada em cursos regulares dos mais variados, como no ensino de idiomas, na capacitação de profissionais, nas graduações e pós-graduações, abordando, por outro lado, uma diversidade de letramentos.

No momento, é crescente o número de instituições e empresas que desenvolvem programas de treinamento de recursos humanos, através da Educação a Distância. As universidades a distância têm incorporado, em seu desenvolvimento histórico, as novas tecnologias de informática e de telecomunicação. (ALVES, 2011, p. 87)

Alves (2011) elabora um histórico da EAD no mundo e no Brasil, demonstrando o imprescindível papel desempenhado tanto pelas instituições quanto pela clientela servida pela $\mathrm{EAD}$, o que resulta inclusive em vencer preconceitos que rondam esta modalidade de ensino, 
como por exemplo, a suposta falta de qualidade de ensino e de aprendizagem. A autora conclui que a EAD "pode ser considerada a mais democrática das modalidades de educação, pois se utilizando de tecnologias de informação e comunicação transpõe obstáculos à conquista do conhecimento" (p. 90).

Nesse contexto, Bonilla e Pretto (2015, p. 149) defendem "o resgate do papel da escola como líder e articuladora do diálogo livre e aberto entre culturas, saberes e linguagens, entre contexto local e não local". Nessa ótica, para os autores, a escola não tem caráter puramente informativo, mas o de produtora de conhecimentos e de cultura, mediante uma elaboração da informação que leva o aluno a ser ativo frente ao conhecimento, sendo que este produto pode navegar de seu próprio contexto a outros.

A internet e seus usos vêm à tona, sustentando uma mudança de considerável abrangência em seu papel. Em seu princípio, ela era denominada como Web 1.0 por ser utilizada apenas como fonte de dados porque "conferia ao usuário um papel de mero consumidor relativamente passivo" (COLL; MONEREO, 2010, p. 28). Atualmente, devido às possibilidades e usos, a internet pode ser denominada de Web 2.0. Bonilla e Pretto (2015) indicam que esta forma de usar a web intensifica a propagação de conhecimentos e novos saberes, a colaboração, a construção de bens culturais e assim de novos produtos, pois, de acordo com os autores, "esse contexto designa uma segunda fase dos serviços web, mais voltados para a produção colaborativa, a participação e a interação" (2015, p. 150).

Ao ler a realidade dessa maneira, aplicando este conhecimento à destinação da Plataforma de Avaliação de Aprendizagem em tempo real, é impossível não pensar numa multimodalidade de gêneros textuais e, consequentemente, de um letramento que dê condições às pessoas de ultrapassarem o simples uso do computador em rede, de modo que possam ir além do acesso à informação.

Obviamente, o acesso à internet passa pela dependência de questões econômicas, políticas e sociais. Porém, para Mosé (2013), a internet democratiza o saber e o poder, sendo que o conteúdo em si mesmo não possui valor na sociedade do conhecimento, mas o produtor do conteúdo tem valor considerável. Tais pessoas, atuantes na Web 2.0, procuram lidar com as informações com sabedoria e conhecimento. Tais pessoas refletem melhor a sociedade do conhecimento, e não da informação. Para Ramal (2013), as informações no atual momento histórico são em tão grande volume a ponto de a pessoa não conseguir acompanhá-las. Para a autora, o perfil das profissões e suas funções estão em constante mudança, fortalecendo cada vez mais uma cibercultura. 
Ramal (2013) considera cibercultura como conjunto de valores, de técnicas materiais e intelectuais, práticas e modos de pensamento que se desenvolvem juntas no ciberespaço. Apesar do tempo não ser linear, surge a noção de tempo real, de navegação simultânea, de janelas e caixas de diálogo. Assim, um elemento decisivo da cibercultura é a facilidade em que o link opera. Dessa maneira, por meio de uma informação durante a navegação na internet é possível ao usuário se conectar a outras informações num movimento sucessivo, o que torna possível diferentes diálogos entre diferentes vozes, sentidos e visões culturais que culminem na construção coletiva do pensamento. Braga (2013) aborda o assunto por outro aspecto:

Outra particularidade está na interatividade constitutiva das trocas comunicativas que ocorrem no meio virtual. Navegando pelas diferentes publicações feitas na rede, o leitor define caminhos de leitura (escolhe links e ordem de acesso às informações disponibilizadas na página). Além disso, como hoje está cada vez mais comum os ambientes digitais oferecerem espaços para comentários e publicação de leitores, na Web 2.0 o leitor contribui diretamente com o sentido do texto lido na medida em que assume o papel de autor, publicando seus comentários ou relacionando o texto lido a outras publicações que circulam na rede. (BRAGA, 2013, p. 45)

Todo o aparato tecnológico, assim como ambientes virtuais e todas as possibilidades e recursos disponibilizados na internet podem estar a serviço da educação. Braga (2013, p. 47) considera que "esses recursos podem compensar, inclusive, algumas deficiências materiais da escola para o desenvolvimento de algumas atividades". Dessa forma, a sociedade da informação e a sociedade do conhecimento precisam caminhar juntas. Pois, não é producente apenas ter acesso à informação, mas além de acessá-la, é preciso saber o que fazer com ela. Em outros termos, ter a informação e não saber como usá-la não demonstra conhecimento, indica apenas capacidade de acesso.

Outro aspecto a ser considerado neste breve exame desta plataforma educacional, é a questão da avaliação das tendências filosóficas e pedagógicas que permeiam o seu funcionamento.

Luckesi (1994) estabelece uma interface entre educação e sociedade de maneira precisa, definindo três tendências filosóficas, muito claras e distintas, prevalentes em diferentes épocas e contextos históricos. O autor (1994, p. 37) aponta para a existência de três caminhos para compreender os rumos da educação na sociedade: "educação como redenção; educação como reprodução; e educação como um meio de transformação da sociedade". Entretanto, dependendo do contexto analisado, tais tendências coexistem na realidade brasileira, pois esta se apresenta ora numa demonstração de mistura dessas características, ora numa preponderância de uma visão de mundo sobre a outra.

De acordo com Luckesi (1994), na abordagem da educação como redenção, os seres humanos são considerados como pertencentes a um grupo denominado sociedade. Entretanto, os 
que vivem à margem desta sociedade, ou os que agem eticamente em desacordo a ela, necessitam da atuação da educação que tem por finalidade curar suas "mazelas" (1994, p. 38). Para o autor (1994), um dos fundamentos desta abordagem está na afirmação de que Comenius identifica as anomalias sociais próprias de sua época no ser humano quanto à sua personalidade de modo geral, “ou seja, na sua sociedade é que se faziam presentes os desequilíbrios como ecos da desarmonia original” (p. 39). Porém, segundo Luckesi (1994), na perspectiva de Comenius, Deus não teria abandonado os seres humanos porque uma possibilidade de regeneração seria por meio da educação.

Diferente da primeira linha de pensamento, a educação como reprodução é "como uma instância dentro da sociedade e exclusivamente ao seu serviço. Não a redime de suas mazelas, mas a reproduz no seu modelo vigente, perpetuando-a, se for possível” (LUCKESI, 1994, p. 41). Dessa maneira, a educação se presta ao serviço de formar profissionais de acordo com a necessidade da sociedade, perpetuando culturalmente a força de trabalho existente. Assim, os descendentes dos médicos serão médicos, bem como o sucessor do operário está dentro da família do operário. Essa modalidade serve até para "uma reprodução da submissão desta à ideologia dominante" (p. 44), por meio de regras morais, de ordem, de respeito, de disciplinarização. O autor ainda expõe que:

Os aparelhos ideológicos de Estado permitem e garantem a hegemonia política, sustentadora do poder, pelo processo de reprodução das relações de produção vigentes na sociedade. A escola, nesse processo, tem papel predominante. A escola, como principal aparelho ideológico de Estado, atua sobre as diversas faixas etárias do cidadão, em cada uma exercendo, em plenitude, seu papel de reprodutora das forças de trabalho. (LUCKESI, 1994, p. 46).

Na terceira abordagem, Luckesi (1994) argumenta a diferenciação sobre as duas anteriores, onde a educação serve de mediadora para uma transformação social sem redimir nem reproduzir a sociedade, mas, nas palavras do autor (1994, p. 48), "realizar um projeto de sociedade; projeto que pode ser conservador ou transformador. No caso, essa tendência não coloca a educação a serviço da conservação". O autor afirma que:

Para tanto, importa interpretar a educação como uma instância dialética que serve a um projeto, a um modelo, a um ideal de sociedade. Ela medeia esse projeto, ou seja, trabalha para realizar esse projeto na prática. Assim, se o projeto for conservador, medeia a conservação; contudo, se o projeto for transformador, medeia a transformação; se o projeto for autoritário, medeia a realização do autoritarismo; se o projeto for democrático, medeia a realização da democracia. (LUCKESI, 1994, p. 49).

Dessa forma, a educação como tendência transformadora permite que os teóricos desta abordagem atuem sobre os condicionantes de sua época com criticidade, para que a educação atinja seus objetivos dentro de aspectos políticos, sociais, econômicos. Como a educação serve a 
um projeto, nunca será simples aos educadores elaborarem ações que contemplem todos os anseios, por isso também, a educação estará inserida dentro de um modelo proposto, que não estará isento de críticas.

Por sua vez, Libâneo (1994) argumenta que a prática docente revela se a abordagem teórica tende para uma pedagogia liberal, ou para uma pedagogia progressista. $\mathrm{O}$ autor foca os seguintes subgrupos inseridos na "Pedagogia liberal: tradicional; renovada progressivista; renovada não-diretiva; tecnicista" (LIBÂNEO, 1994, p. 54). E ainda os seguintes subgrupos na "Pedagogia progressista: libertadora; libertária; crítico-social dos conteúdos" (1994, p. 54).

Para Libâneo (1994), na pedagogia liberal, a função da escola enquanto instituição educacional é tornar apta cada pessoa a desempenhar seu papel dentro da sociedade "de acordo com as aptidões individuais, por isso os indivíduos precisam aprender a se adaptar aos valores e às normas vigentes na sociedade de classes através do desenvolvimento da cultura individual" (LIBÂNEO, 1994, p. 55). De acordo como o autor (1994), já a pedagogia progressista analisa a sociedade criticamente e observa os objetivos sociopolíticos implícitos na educação.

Dentro de cada tendência e seus subgrupos, a escola tem seu papel definido dentro da sociedade, apresentando métodos, estratégias, conteúdos, pressupostos teóricos, práticas e relacionamento professor e aluno próprios de cada abordagem. Ora tais tendências podem se distanciar ou ora se aproximar, dependendo do contexto, das abordagens, dos pressupostos utilizados e das motivações que levam o educador a elaborar sua práxis.

Outra consideração no contexto da nossa investigação guarda relação com a abordagem pedagógica construída entre ensinante e aprendente no ambiente virtual de aprendizagem. Tal abordagem dá-se numa vertente liberal direcionada ao público adulto. Trata-se de uma perspectiva adotada pela Andragogia. Nas palavras de Gil (2012, p. 12), refere-se "à arte e à ciência de orientar os adultos a aprender".

Na abordagem da Andragogia, segundo Gil (2012), “o adulto está pronto para aprender o que decide aprender" (p. 13). Nesta perspectiva, o aluno é um aprendente "responsável por sua aprendizagem" (p.12). Ele está inserido num processo autodirigido/autorregulatório e delimita seu próprio percurso nos estudos. Neste pressuposto, a motivação para o aprendizado é de caráter interno, como "reconhecimento, autoconfiança" (GIL, 2012, p. 12), e externo como, por exemplo, a capacitação prática para o trabalho.

\section{ANÁLISE DA PLATAFORMA}

A análise das informações colhidas na plataforma evidenciou que o site oferece o uso de ferramentas importantes para a facilitação do desenvolvimento do conhecimento do aprendente. $\mathrm{O}$ 
site permite: uso de fórum; acesso do usuário ao conhecimento a que se propõe, sendo que, o usuário é o consumidor da informação por meio de programas disponíveis no site e/ou na rede mundial; troca de mensagens entre o aluno e o professor, e vice-versa, bem como o professor com o grupo, e o aluno com o aluno; uso de estratégias autorregulatórias e estratégias cognitivas.

Observamos que: apesar da possibilidade de troca de ideias entre os usuários do sistema possibilitando avanço real de aprendizagem nos conteúdos, nas tarefas e nas avaliações, a produção textual nem sempre é colaborativa na relação aprendente-aprendente; há apresentação de sugestões de referências nos assuntos trabalhados e disponibilidade de acessos a revistas nas áreas afins; as orientações do tutor e as trocas de conhecimento entre ele e os aprendentes são imprescindíveis para produção textual colaborativa.

Sobre a relação professor e aluno, observamos que esta permite a reelaboração de tarefas inadequadas com foco no aprendizado do aluno. Nesse ponto é importante salientar que as informações coletadas demonstram que a plataforma educacional mescla tendências filosóficas reprodutoras e transformadoras. Usamos a figura 7 para ilustrar essa situação.

Figura 7: Caixa de diálogo, Comentários do Professor

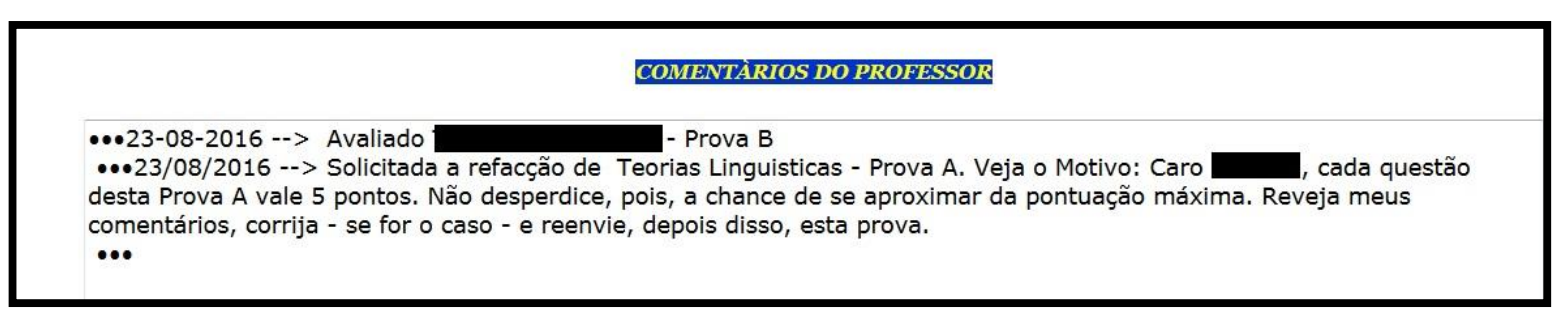

Fonte: http://www.professorcarlosoliveira.com/MDV/Plataforma.html (2016)

Esta é uma imagem fruto da interação do aprendente com o ensinante. A imagem ilustra o momento após o aprendente ter se submetido ao estudo e a elaboração de atividades no site. $\mathrm{O}$ objetivo da caixa de diálogo ser chamada de Comentários do professor indica o tipo de interação entre o aprendente e o ensinante. O conteúdo da mensagem indica que o foco do ensinante é que o aprendente obtenha a maior pontuação possível refazendo a tarefa. Para tanto, é necessário que o aprendente reveja as observações do ensinante, elabore as correções e submeta o trabalho a um novo parecer do ensinante. Somente após esse processo, o aprendente deve reenviar a tarefa em definitivo pelo site. Para Vasconcellos (1992) esse é um processo que permite ao ensinante conhecer a realidade do aprendente e, dessa maneira, o ensinante aprende junto ao aprendente por intermédio do ponto de vista expresso pelo aprendente nas tarefas elaboradas.

Nesse sentido, o site mescla tendências filosóficas reprodutoras de conhecimento e transformadoras ao mesmo tempo, já que a valorização das atividades não termina com a primeira 
correção das tarefas pelo ensinante, visto que o foco está no produto final resultado do processo de construção colaborativa do conhecimento.

A próxima imagem, figura 8, revela o reforço na pretensão de valorizar o processo de aprendizagem. Ela permite observar que o procedimento para construção das provas do aprendente acontece no momento da enunciação entre ensinante e aprendente, o que indica a valorização do acerto durante o processo de aprendizagem. Se o site utilizasse um processo tradicional de ensino e aprendizagem, o erro inicial seria contado enquanto valor negativo definitivo para o aprendente.

Figura 8: Caixa de diálogo, Intervenção do Professor

\section{Questão 2: Preencha as LACUNAS}

\section{INTERVENCÃO DO PROFESSOR:}

VC acha mesmo que 'pertinência' é a atividade ou casualidade cujos efeitos não passam do agente?

VC acha mesmo que 'processo' é uma sequência contínua de fatos que apresentam certa unidade, ou que se reproduzem com certa regularidade? - $\rightarrow$ (postada em 2016/08/23 07:08:00)

Agora a coisa ficou mais complicada ainda, pois você diz que:

- 'imanência' é uma coisa já pronta e finalizada.

- 'produto' que é a atividade ou casualidade cujos efeitos não passam do agente

- 'pertinência' é uma sequência contínua de fatos que apresentam certa unidade, ou que se reproduzem com certa regularidade

o que isso?!!! $\rightarrow$ (postada em 2016/08/24 07:08:12)

AGORA ESTÁ CORRETO

$\rightarrow$ (postada em 2016/08/27 13:08:21)

Fonte: http://www.professorcarlosoliveira.com/MDV/Plataforma.html (2016)

O conteúdo da comunicação do ensinante com o aprendente ilustrado na figura 8 , apesar de não conter a tarefa elaborada pelo aprendente, demonstra que o ensinante interveio por duas vezes junto ao aprendente para que a tarefa fosse elaborada adequadamente - dias 23 e 24 de agosto de 2016, conforme figura 8. As observações do ensinante tiveram por base os erros cometidos pelo aprendente. Após apontar o erro do aprendente, o ensinante questionou de forma direta a posição do aprendente sobre o assunto da tarefa. Assim que o produto final foi apresentado com as adequações necessárias, a Questão 2 foi declarada pelo ensinante como correta, na terceira intervenção.

Procedemos com nossas análises a respeito dos Princípios Norteadores do trabalho utilizando o MDV, com a exposição das figuras 9 e 10. A transparência da plataforma sobre tais pressupostos é adequada, e suficientemente observável. O aprendente pode acessar tais informações na página inicial da plataforma ao clicar no botão denominado Menu, e escolhendo a opção Cursos/Disciplinas oferecidas é aberta uma nova guia. O projeto do MDV é apresentado na página 2 desta nova guia. Há um link instalado na imagem da lupa, figura 9. 
Figura 9: Caixa de diálogo

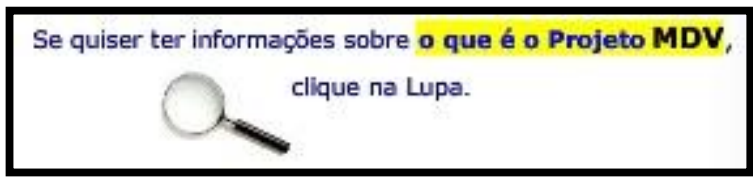

Fonte: https://user-68731098986.cld.bz/Cursos-Disciplinas/2 (2016)

Este link direciona o usuário a uma nova guia aberta denominada Princípios norteadores, figura 10 .

Figura 10: Princípios Norteadores

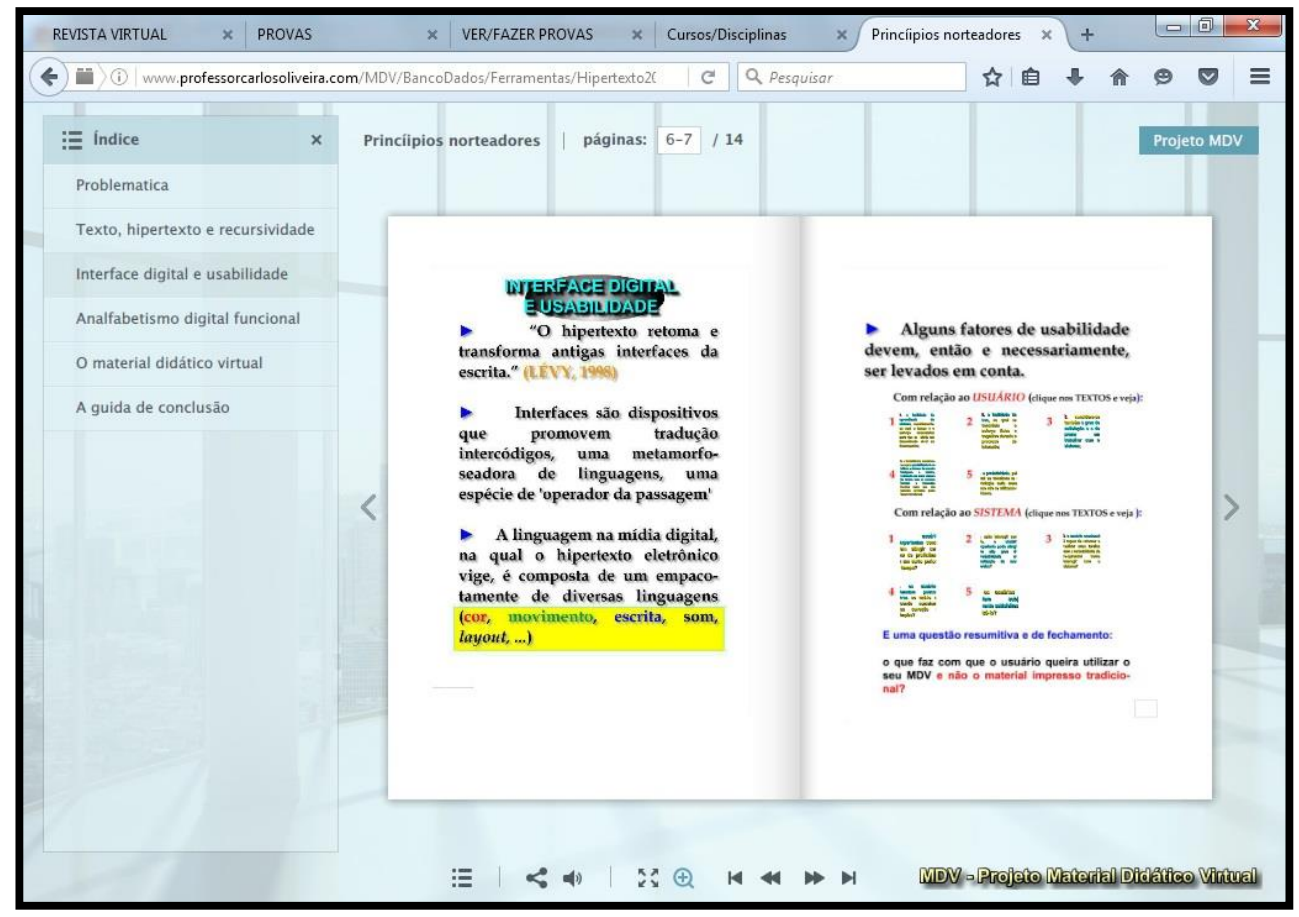

Fonte: hhtp://www.professorcarlosoliveira.com (2016)

Nesta parte do MDV, como vemos na figura 10, o site informa acerca de fatores relacionados ao sistema e ao usuário do sistema. Tais informações refletem parte dos princípios norteadores do trabalho desenvolvido nesta plataforma educacional.

\section{CONCLUSÃO}

A partir dos resultados desse estudo, primeiramente, podemos concluir que a Plataforma de Avaliação de Aprendizagem em tempo real pode ser considerada como uma ferramenta de Web 2.0 que cumpre com o objetivo de avaliar a clientela do site, direciona o foco dos estudos dos aprendentes por meio das atividades propostas e da mediação assincrônica do ensinante. 
A relação entre professor e aluno é observável nos papéis desempenhados por ensinante e aprendente. Não há, em nossa análise, evidência de interação de aprendente com outros aprendentes, apesar de essa possibilidade existir no site. Ao aprendente cabe a disciplina pessoal de se dispor a elaborar as atividades avaliativas mediante o estudo proposto pelo MDV, assim como submetê-las à análise do ensinante antes de sua conclusão final.

$\mathrm{O}$ uso do site como ferramenta permite ao ensinante conferir e avaliar os trabalhos propostos com vistas ao processo e ao produto final dos trabalhos. Como ferramenta, o site contribui com o aprendente no sentido de poder estudar e elaborar as atividades avaliativas fora dos limites de horários predeterminados por um cronograma de sala de aula tradicional.

Em relação aos conteúdos postados no site, predominantemente, possuem tendências filosóficas transformadoras e reprodutoras de saberes e conhecimentos por meio de uma abordagem pedagógica direcionada adequadamente a um público adulto.

Por fim, a Plataforma de Avaliação de Aprendizagem em tempo real, inserida no Programa de Mestrado em Linguística Aplicada da Universidade de Taubaté cumpre com o propósito de ser uma ferramenta que contribui com a formação do aprendente.

\section{REFERÊNCIAS}

ALVES, Lucineia. Educação a distância: conceitos e história no Brasil e no mundo. Revista Brasileira de Aprendizagem Aberta e a Distância. v. 10, p. 83-92, 2011. Disponível em: <http://www.abed.org.br/revistacientifica/Revista_PDF_Doc/2011/Artigo_07.pdf> Acesso em: 01 abr. 2016.

ANDRADE, Márcia Siqueira de. Ensinante e aprendente: a construção da autoria de pensamento. Construção psicopedagógica. v.14, n. 1. São Paulo, dez. 2006. Disponível em: <http://pepsic.bvsalud.org/scielo.php?script=sci_arttext\&pid=S1415-69542006000100005> Acesso em: 10 nov. 2016.

BONILLA, Maria Helena Silveira; PRETTO, Nelson de Luca. As tecnologias digitais: construindo uma escola ativista. In: BRAGA, Denise Bértoli. (Org.). Tecnologias digitais da informação e comunicação e participação social: possibilidades e contradições. São Paulo: Cortez, 2015. p. 149-166.

BRAGA, Denise Bétoli. Ambientes digitais: reflexões teóricas e práticas. São Paulo: Cortez, 2013.

COLL, César; MONEREO, Carles. Educação e aprendizagem no século XXI: novas ferramentas, novos cenários, novas finalidades. In: COLL, César; MONEREO, Carles. Psicologia da educação virtual: aprender e ensinar com as tecnologias da informação e da comunicação. Disponível em: <http://www.larpsi.com.br/media/mconnect_uploadfiles/c/a/cap_01klp.pdf> Acesso em: 26 maio 2016. 
CRUZ, Maria Waleska. A pesquisa em sala de aula - interlocução entre teoria e prática: uma crítica na trama necessária. In: RAMOS, Maria Beatriz Jacques; FARIA, Elaine Turk. (Org.). Aprender e ensinar: diferentes olhares e práticas. Porto Alegre: EDIPUCRS, 2011. p. 26-56. Disponível em: <http://ebooks.pucrs.br/edipucrs/Ebooks/Pdf/978-85-397-0076-9.pdf> Acesso em: 10 nov. 2016. p. 26-56

CRUZ, Paula Falcão. Autoria de pensamento e construção de conhecimento: uma questão de aprendizagem. In: RAMOS, Maria Beatriz Jacques; FARIA, Elaine Turk. (Org.). Aprender e ensinar: diferentes olhares e práticas. Porto Alegre: EDIPUCRS, 2011. p. 87-96. Disponível em: <http://ebooks.pucrs.br/edipucrs/Ebooks/Pdf/978-85-397-0076-9.pdf> Acesso em: 10 nov. 2016.

FREIRE, Paulo. A importância do ato de ler: em três artigos que se completam. 38. ed. São Paulo: Cortez, 1999.

GIL, Antônio Carlos. Didática do ensino superior. São Paulo: Atlas, 2012.

LIBÂNEO, José Carlos. Tendências pedagógicas na prática escolar. In: LUCKESI, Cipriano Carlos. Filosofia da Educação. São Paulo: Cortez, 1994. p. 53-75. Disponível em: <http://www.biblioteca.sumare.edu.br/vinculos/PDF_OBRAS/3307_miolo.pdf> Acesso em: 12 mar. 2016.

LUCKESI, Cipriano Carlos. Educação e sociedade: redenção, reprodução e transformação. In: LUCKESI, Cipriano Carlos. Filosofia da Educação. São Paulo: Cortez, 1994. p. 37-52. Disponível em: <http://www.biblioteca.sumare.edu.br/vinculos/PDF_OBRAS/3307_miolo.pdf> Acesso em: 12 mar. 2016.

MOSÉ, Viviane. Educação na sociedade do conhecimento. UNA TV, 04 jul. 2013. Disponível em: <https://www.youtube.com/watch?v=vqkUWJINT_k> Acesso em: 29 mar. 2016.

RAMAL, Andrea Cecília. Novas formas de pensar e aprender. Loyola Multimídia, 29 abr. 2013. Disponível em: <https://www.youtube.com/watch?v=Dwpr0HZJvD8> Acesso em: 29 mar. 2016.

SOARES, Magda. Novas práticas de leitura e escrita: letramento na cibercultura. Disponível em: <http://www.scielo.br/pdf/es/v23n81/13935.pdf> Acesso em: 26 maio 2016.

VASCONCELLOS, Celso dos S. Metodologia Dialética em Sala de Aula. In: Revista de Educação AEC. n. 83. Brasília, abr. 1992. Disponível em:

<http://www.celsovasconcellos.com.br/Textos/MDSA-AEC.pdf> Acesso em: 06 abr. 2017. 